\title{
Safety application of muscle relaxants and the traditional low-frequency ventilation during the flexible or rigid bronchoscopy in patients with central airway obstruction: a retrospective observational study
}

Jing-Jin Li ${ }^{\dagger}$, Nan Li ${ }^{\dagger}$, Wei-Jia Ma, Ming-Xue Bao, Zi-Yang Chen and Zheng-Nian Ding*

\begin{abstract}
Background: Bronchoscopy treatments of central airway obstruction (CAO) under general anesthesia are high-risky procedures, and posing a giant challenge to the anesthesiologists. We summarized and analyzed our clinical experience in patients with CAO undergoing flexible or rigid bronchoscopy, to estimate the safety of skeletal muscle relaxants application and the traditional Low-frequency ventilation.
\end{abstract}

Methods: Clinical data of 375 patients with CAO who underwent urgent endoscopic treatments in general anesthesia from January 2016 to October 2019 were retrospectively reviewed. The use ratio of skeletal muscle relaxants, dose of skeletal muscle relaxants used, the incidence of perioperative adverse events, adequacy of ventilation and gas exchange, post-operative recovery between rigid bronchoscopy and flexible bronchoscopy therapy, and risk factors for postoperative ICU admission were evaluated.

(Continued on next page)

\footnotetext{
* Correspondence: crystalni@qq.com

${ }^{\dagger}$ Jing-Jin Li and Nan Li contributed equally to this work.

Department of Anesthesiology and Perioperative Medicine, The First

Affiliated Hospital with Nanjing Medical University, Nanjing 210029, Jiangsu,

China
}

C C The Author(s). 2021 Open Access This article is licensed under a Creative Commons Attribution 4.0 International License, which permits use, sharing, adaptation, distribution and reproduction in any medium or format, as long as you give appropriate credit to the original author(s) and the source, provide a link to the Creative Commons licence, and indicate if changes were made. The images or other third party material in this article are included in the article's Creative Commons licence, unless indicated otherwise in a credit line to the material. If material is not included in the article's Creative Commons licence and your intended use is not permitted by statutory regulation or exceeds the permitted use, you will need to obtain permission directly from the copyright holder. To view a copy of this licence, visit http://creativecommons.org/licenses/by/4.0/ The Creative Commons Public Domain Dedication waiver (http://creativecommons.org/publicdomain/zero/1.0/) applies to the data made available in this article, unless otherwise stated in a credit line to the data. 
(Continued from previous page)

Results: Of the 375 patients with CAO, 204 patients were treated with flexible bronchoscopy and 171 patients were treated with rigid bronchoscopy. Muscle relaxants were used in 362 of 375 patients (including 313 cisatracurium, 45 rocuronium, 4 atracurium, and 13 unrecorded). The usage rate of muscle relaxants ( $96.5 \%$ in total) was very high in patients with CAO who underwent either flexible bronchoscopy (96.6\%) or rigid bronchoscopy (96.5\%) therapy. The dosage of skeletal muscle relaxants (Cisatracium) used was higher in rigid bronchoscopy compared with flexible bronchoscopy therapy $(10.8 \pm 3.8$ VS $11.6 \pm 3.6 \mathrm{mg}$, respectively, $p<0.05)$. No patient suffered the failure of ventilation, bronchospasm and intraoperative cough either in flexible or rigid bronchoscopy therapy. Hypoxemia was occurred in 13 patients (8 in flexible, 5 in rigid bronchoscopy) during the procedure, and reintubation after extubation happened in 2 patients with flexible bronchoscopy. Sufficient ventilation was successfully established using the traditional Low-frequency ventilation with no significant carbon dioxide accumulation and hypoxemia occurred both in flexible and rigid bronchoscopy group ( $p>0.05$ ). Three patients ( 1 in flexible and 2 in rigid) died, during the post-operative recovery, and the higher grade of American Society of Anesthesiologists (ASA) and obvious dyspnea or orthopnea were the independent risk factors for postoperative ICU admission.

Conclusion: The muscle relaxants and low-frequency traditional ventilation can be safely used both in flexible and rigid bronchoscopy treatments in patients with CAO. These results may provide strong clinical evidence for optimizing the anesthesia management of bronchoscopy for these patients.

Keywords: Anesthesia management, Bronchoscopy, Central airway obstruction, Muscle relaxants, Traditional lowfrequency ventilation

\section{Background}

The quality of life of the patients is seriously impaired by severe $\mathrm{CAO}$ presented as severe dyspnea, stridor, or even respiratory failure. $\mathrm{CAO}$ is a potentially lifethreatening condition, which has been treated in many ways $[1,2]$. For patients amenable to surgery, resection and reconstruction is the best therapeutic option. However, whenever surgery is not feasible, endoscopic therapies are needed $[3,4]$.

Nowadays, endoscopic treatment has been widely used as an effective method to treat $\mathrm{CAO}$, palliating dyspnea in some cases of malignant obstruction and even be curative in some cases of benign tumor or inflammation [5-7]. Such procedures are mainly performed using rigid or flexible bronchoscope.

These interventions are high-risky procedures, posing a giant challenge to the anesthesiologists. How to establish adequate gas exchange to maintain the life of patients and allow good surgical access is what should be considered during anesthesia [6, 8]. Furthermore, the choice of ventilation strategy and the use of skeletal muscle relaxants are still significant issues for anesthesiologists to consider.

In this article, we summarized and analyzed our clinical experience in anesthesia management in patients with CAO undergoing flexible or rigid bronchoscopy in general anesthesia from January 2016 to October 2019, including the use of muscle relaxants and the traditional Low-frequency ventilation, to estimate the safety of skeletal muscle relaxants application and the traditional Low-frequency ventilation.

\section{Methods}

\section{Study subjects}

A total of 427 patients with CAO underwent flexible bronchoscopy or rigid bronchoscopy in the First Affiliated Hospital with Nanjing Medical University from January 2016 to October 2019, of which the clinical data of 375 patients were retrospectively reviewed. Inclusion criteria: (1) Patients with central airway obstruction;(2) need urgent flexible or rigid bronchoscope surgery with various methods for controlling the airway, such as electrocoagulation (including snare electrocoagulation, electrocautery, high-frequency electrosurgical ablation, ect.), electrocautery, cryotherapy, argon plasma coagulation, balloon inflation and stent placement or removal (Table 1); (3) need general anesthesia. Exclusion criteria: (1) patients with intermedius space occupation or lower bronchus stenosis; (2) patients with mediastinal tumors, foreign body; (3) patients with bronchopleural, bronchoesophageal, bronchomediastinal or tracheoesophageal fistula, (4) patients who just underwent biopsy by bronchoscopy; (5) incomplete data or associated anomalies. This study has passed deliberation of the Clinical Ethics Committee of the First Affiliated Hospital with Nanjing Medical University (approval number: 2019-SR-505).

\section{Anesthesia management}

General anesthesia was conducted by anesthesiologists. All patients were monitored with Electrocardiograph (ECG), Pulse Oxygen Saturation $\left(\mathrm{SpO}_{2}\right)$, invasive arterial blood pressure (IABP), and given pre-oxygenation with 
Table 1 Patient baseline characteristics

\begin{tabular}{|c|c|c|c|c|}
\hline \multirow[t]{2}{*}{ Characteristics } & \multicolumn{3}{|l|}{$\mathrm{N}(\%)$} & \multirow[t]{2}{*}{$P$ value } \\
\hline & Flexible (204) & Rigid (171) & Total (375) & \\
\hline Age, media (range), year & $63(16 \sim 89)$ & $62(12 \sim 87)$ & $62(12 \sim 89)$ & 0.70 \\
\hline Gender (M:F) & $115: 89$ & $106: 65$ & $221: 154$ & 0.271 \\
\hline BMI (\%) & $22.5 \pm 3.4$ & $21.8 \pm 3.5$ & $22.2 \pm 3.4$ & 0.127 \\
\hline \multicolumn{5}{|l|}{ ASA } \\
\hline$\|\sim\|$ & $156(76.5 \%)$ & $127(74.3 \%)$ & $286(75.5 \%)$ & \multirow[t]{3}{*}{0.915} \\
\hline IV & $44(21.6 \%)$ & $39(22.8 \%)$ & $84(22.1 \%)$ & \\
\hline V & $4(2.0 \%)$ & $5(2.9 \%)$ & $9(2.4 \%)$ & \\
\hline \multicolumn{5}{|l|}{ Airway procedures } \\
\hline Endobronchial stenting & 91 (44.6\%) & 87 (50.9\%) & $178(47.5 \%)$ & 0.226 \\
\hline Balloon dilatation & $29(14.2 \%)$ & $25(14.6 \%)$ & $54(14.4 \%)$ & 0.912 \\
\hline Argon plasma coagulation & $14(6.9 \%)$ & $10(5.8 \%)$ & $24(6.4 \%)$ & 0.689 \\
\hline Cryoablation & $12(5.9 \%)$ & $8(4.7 \%)$ & $20(5.3 \%)$ & 0.605 \\
\hline Endobronchial laser & $7(3.4 \%)$ & $3(1.8 \%)$ & $10(2.7 \%)$ & 0.315 \\
\hline Electrocoagulation & 89 (43.6\%) & $78(45.6 \%)$ & $167(44.5 \%)$ & 0.700 \\
\hline Stent removal & $3(1.5 \%)$ & $4(2.3 \%)$ & $7(1.9 \%)$ & 0.536 \\
\hline
\end{tabular}

$B M I$ Body Mass Index, ASA American Society of Anesthesiologist

$100 \%$ oxygen, $8 \sim 10 \mathrm{~L} / \mathrm{min}$ for at least $3 \mathrm{~min}$ before anesthesia induction. General anesthesia was induced with etomidate or propofol, fentanyl or together with remifentanil, cisatracurium or rocuronium, with or without midazolam, and maintained with propofol and remifentanil. The depth of anesthesia was adjusted according to the intensity of surgical stimulation and hemodynamic indicators.

Patients in flexible group was ventilated by Laryngeal mask airway (LMA) or endotracheal intubation. Patients in rigid group were ventilated by a side port of rigid bronchoscope during the procedure, and LMA insertion or endotracheal intubation was performed immediately after the procedure for sustaining the ventilation. 8-10 L/ min pure oxygen was maintained during the whole operation. When the patient's $\mathrm{SpO}_{2}$ dropped below $90 \%$, the operation was stopped and the scope was removed to ventilate the patient. After a few minutes of ventilation, when the patient's $\mathrm{SpO}_{2}$ reached 99-100\%, the operation continued. The patients were sent to the recovery room for resuscitation after operation, and muscle relaxant antagonists were given at appropriate time for patients who had no contraindications. Patients with the modified Aldrete score above 9 points were sent back to the general ward, while patients with the modified Aldrete score below 9 points or couldn't be extubated were sent to intensive care unit (ICU).

\section{Outcome measurements}

On the basis of the anesthetic record of each patient, we analyzed the use rate of muscle relaxants, the dosage of muscle relaxants, operation duration, recovery time, artery blood gas, End-tidal carbon dioxide $\left(\mathrm{EtCO}_{2}\right)$, the incidence of perioperative adverse events, postoperative outcomes and the risk factors for patients entering the ICU after surgery. The perioperative adverse events were failure of ventilation, bronchospasm, intraoperative cough, and hypoxemia, hypercapnia, reintubation after extubating. Bronchospasm was defined as wheezing or significantly increased airway pressure during mechanical ventilation, hypoxemia was defined as oxygen saturation $<90 \%$, and hypercapnia is the elevation in the partial pressure of carbon dioxide $\left(\mathrm{PaCO}_{2}\right)$ above 45 $\mathrm{mmHg}$.

\section{Statistical analysis}

SPSS version 23.0 program was used for statistical analysis, and measurement data are expressed as mean \pm standard deviation $(\mathrm{X} \pm \mathrm{SD})$, and counting data are expressed by frequency (n) or rate (\%). Analyses are compared between flexible bronchoscopy and rigid bronchoscopy. Chi-square test was used for count data, $\mathrm{t}$-test for measurement data, paired $\mathrm{t}$ test for paired groups measurement date, Bivariate Correlation analysis for the correlation between two groups, and Binary Logistic regression analysis for risk factors of postoperative ICU admission. Although the amount of blood gas analysis samples obtained was small (flexible group $n=18$, rigid group $n=17$ ) when reviewing the data, we still performed a correlation analysis of carbon dioxide partial pressure and operation time based on the existing data 
by Bivariate Correlation analysis. Statistical significance was set at $P<0.05$, and all tests were two-tailed.

\section{Results}

\section{Clinical characteristics of included patients}

Baseline clinical characteristics of included patients are shown in Table 1. Of the 375 patients with CAO, 204 received flexible bronchoscopy treatments (flexible group) while the other 171 received rigid bronchoscopy treatments (rigid group). As shown in Table 1, there were no significant differences in age, gender, BMI (body mass index), and ASA grades between the two groups ( $p>$ $0.05)$. What's more, one or more airway procedures may be performed in a patient, such as placing a stent and then performing balloon dilation, ect. Endobronchial stenting (44.6\% in flexible and $50.9 \%$ in rigid) and Electrocoagulation $(43.6 \%$ in flexible, $45.6 \%$ in rigid) were the most utilized interventions during the flexible or rigid bronchoscopy (Table 1), and there was no difference in airway procedures between the two groups $(p>0.05)$.

The malignant tumor is the main stenosis pathogen (68.8\% in total, $64.4 \%$ in flexible and $73.7 \%$ in rigid, respectively, $p>0.05$ ), and the main cause of CAO for performing flexible or rigid bronchoscopy is primary lung tumor $(36.3 \%$ in total, $38.7 \%$ in flexible and $33.3 \%$ in rigid, respectively, $p>0.05$ ). Other causal diseases are esophageal cancer, tracheal tumor, scarring, postplacement of stenting, thyroid tumor, lymphoma and tuberculosis (Table 2). The location of CAO in tracheal diagnosed by helical computed tomography $(\mathrm{CT})$ scan or bronchoscopy was $66.7 \%(68.8 \%$ in total, $64.4 \%$ in flexible and $73.7 \%$ in rigid, respectively, $p>0.05$ ), while main bronchus (left or/and right main bronchus) stenosis was $33.3 \%$ (Table 2).

\section{The use of skeletal muscle relaxants}

The safety of skeletal muscle relaxants used in patients with tracheal stenosis is a big challenge for anesthesiologists. In this research, skeletal muscle relaxants were used in $96.5 \%$ (362 patients) of the 375 included patients, in which $83.5 \%$ (313 patients) were cisatracurium, $12.0 \%$ (45 patients) rocuronium and $1.1 \%$ (4 patients) atracurium. The use rate of skeletal muscle relaxants was $96.5 \%$ (79.5\% cistracurium, $15.8 \%$ rocuronium, $1.2 \%$ atracurium) in rigid bronchoscopy patients, and it was $96.6 \%$ (86.8\% cistracurium, $8.8 \%$ rocuronium, $1.0 \%$ atracurium) in flexible bronchoscopy patients (Table 3 ), and there was no difference between the two groups $(p>0.05)$.

Although $96.5 \%$ of patients with CAO undergoing flexible or rigid bronchoscopy therapy used skeletal muscle relaxants, we found no patients with the failure of ventilation (Table 4). What's more, no patients suffered bronchospasm or cough, 13 patients (8 in flexible, 5 in rigid) suffered the hypoxemia during the procedure, and two patients $(0.05 \%)$ were reintubated after awakening due to dyspnea after extubating (sent to ICU after adjusting the position of the bracket). There was no difference between the two groups in perioperative adverse events (Table 4). In addition, the dosage of skeletal muscle relaxants (Cisatracium) used was higher in rigid bronchoscopy compared with flexible bronchoscopy therapy $(10.8 \pm 3.8$ VS $11.6 \pm 3.6 \mathrm{mg}$, respectively, $p<$ $0.05)$. There was no difference between the two groups in procedure duration $(41.4 \pm 32.5$ VS $41.5 \pm 29.9 \mathrm{~min}$,

Table 2 Etiology and location of patients with CAO undergoing flexible bronchoscopy or rigid bronchoscopy

\begin{tabular}{|c|c|c|c|c|}
\hline & \multicolumn{3}{|l|}{ N (\%) } & \multirow[t]{2}{*}{$P$ value } \\
\hline & Flexible (204) & Rigid (171) & Total (375) & \\
\hline \multicolumn{5}{|l|}{ Etiology of CAO } \\
\hline Lung tumor & 79 (38.7\%) & $57(33.3 \%)$ & $136(36.3)$ & \multirow[t]{8}{*}{0.418} \\
\hline Esophageal cancer & $45(22.1 \%)$ & $42(24.6 \%)$ & $87(23.2)$ & \\
\hline Tracheal tumor & 39 (19.2\%) & $26(15.2 \%)$ & 65 (17.4\%) & \\
\hline Scarring & $25(12.3 \%)$ & $23(13.5 \%)$ & $48(12.8 \%)$ & \\
\hline Post-placement of stenting & $9(4.4 \%)$ & $13(7.9 \%)$ & $22(5.6 \%)$ & \\
\hline Thyroid tumor & $4(2.0 \%)$ & $4(2.3 \%)$ & $8(2.1 \%)$ & \\
\hline Lymphoma & $1(0.5 \%)$ & $3(1.8 \%)$ & $4(1.1 \%)$ & \\
\hline Tuberculosis & $2(1.0 \%)$ & $3(1.8 \%)$ & $5(1.3 \%)$ & \\
\hline \multicolumn{5}{|l|}{ Benign/Malignant } \\
\hline Benign & $72(35.3 \%)$ & 45 (26.3\%) & $117(31.2 \%)$ & \multirow[t]{2}{*}{0.062} \\
\hline Malignant & $132(74.7 \%)$ & $126(73.7 \%)$ & $258(68.8 \%)$ & \\
\hline \multicolumn{5}{|l|}{ Location of CAO } \\
\hline Tracheal & $130(63.7 \%)$ & $120(73.2 \%)$ & $250(66.7 \%)$ & \multirow[t]{2}{*}{0.187} \\
\hline Left or right main bronchus & 74 (36.3\%) & $51(29.8 \%)$ & 125 (33.3\%) & \\
\hline
\end{tabular}


Table 3 Utilization rate of skeletal muscular relaxants in patients with CAO undergoing flexible bronchoscopy or rigid bronchoscopy

\begin{tabular}{lllll}
\hline $\begin{array}{l}\text { muscular } \\
\text { relaxants }\end{array}$ & $\mathbf{N}(\%)$ & & & $P$ value \\
\cline { 2 - 4 } & Flexible (204) & Rigid (171) & Total (375) & \\
\hline Cisatracurium & $177(86.8 \%)$ & $136(79.5 \%)$ & $313(83.5 \%)$ & 0.224 \\
Rocuronium & $18(8.8 \%)$ & $27(15.8 \%)$ & $45(12.0 \%)$ & \\
Atracurium & $2(1.0 \%)$ & $2(1.2 \%)$ & $4(1.1 \%)$ & \\
No recorded & $7(3.4 \%)$ & $6(3.5 \%)$ & $13(3.5 \%)$ & \\
\hline
\end{tabular}

respectively, $p>0.05)$ and awakening duration (25.3 \pm 21.0 VS $25.8 \pm 17.3 \mathrm{~min}$, respectively, $p>0.05)$.

\section{Assessment of traditional low-frequency ventilation}

Different from High or Low frequency jet ventilation, the traditional Low-frequency ventilation was used in all patients with $\mathrm{CAO}$. $\mathrm{EtCO}_{2}$ and partial pressure of carbon dioxide in artery blood $\left(\mathrm{PaCO}_{2}\right)$ was investigated to evaluate the adequacy of ventilation and gas exchange (Fig. 1). The level of $\mathrm{EtCO}_{2}$ in patients after either flexible bronchoscopy or rigid bronchoscopy both increased $(35.76 \pm 7.71$ VS $40.19 \pm 6.04 \mathrm{mmHg}, 31.72 \pm 6.32 \mathrm{VS}$ $37.88 \pm 6.15 \mathrm{mmHg}$, respectively, $p<0.05)$, but the increased extents were not very remarkable (Fig. 1a). The level of $\mathrm{EtCO}_{2}$ in the blood gas collected immediately after the operation also increased compared with that before the operation both in two groups $(42.25 \pm 10.54$ VS $55.35 \pm 17.54 \mathrm{mmHg}, 43.93 . \pm 13.70$ VS $59.50 \pm 24.24$ $\mathrm{mmHg}$, respectively, $p<0.05)$, that is, most patients suffered hypercapnia during the procedure (Fig. 1b). But the occurrence of hypercapnia has no correlation with the duration of operation both in flexible bronchoscopy and rigid bronchoscopy therapy in patients with $\mathrm{CAO}$ (Fig. 2).

Of all patients, only $13(8$ in flexible, 5 in rigid $)$ had the lowest $\mathrm{SpO}_{2}$ drop below 90\%, while 33 (15 in flexible, 18 in rigid) fluctuated between 90 and 95\% during the procedure (Table 5). $\mathrm{PaO}_{2}$ values were higher in the flexible group than in the rigid group during the therapy, yet both above $200 \mathrm{mmHg}$ $(293.2 \pm 40.07$ vs $204.1 \pm 41.03 \mathrm{mmHg})$, but had no significant difference $(p>0.05)$.

\section{Post-operative recovery}

Following the procedure, 323 patients were sent back to the ward safely after waking up. Fifty-two patients were transferred to ICU due to poor general condition, of which 3 patients died ( 2 due to hemoptysis and 1 due to acute myocardial infarction) in Day2 after the bronchoscopy therapy (Table 6). The risk factors (including age, ASA, hypertension, diabetes, abnormal ECG, coronary heart disease, lung infection, respiratory failure before procedure, cerebrovascular disease) for patients entering ICU after surgery were conducted in this research. The correlation regression analysis indicated that higher ASA grade and obvious dyspnea or orthopnea were the independent risk factors for postoperative ICU admission (Table 7).

\section{Discussion}

Central airway stenosis is known worldwide as a lifethreatening condition with many causes [9-11]. In this study, we retrospectively reviewed 375 cases with CAO undergoing bronchoscopy with general anesthesia. The causes of CAO were primary tracheal tumors or lung cancer, esophageal cancer, scarring after tracheotomy, post-placement of stenting, mediastinal tumor, pulmonary metastatic tumor, and tracheomalacia etc.. As complications of these diseases, tracheal stenosis can be treated in many ways. Surgery may be the preferred approach, but not all patients are appropriate surgical candidates [4]. Therefore, bronchoscopy treatment remains the best tool for the safest management of airway obstructions, and provides prompt and durable palliation to patients ineligible for surgical treatment $[3,7,12,13]$.

Table 4 The comparison of skeletal muscular relaxants and perioperative adverse events between flexible bronchoscopy and rigid bronchoscopy therapy in patients with CAO

\begin{tabular}{|c|c|c|c|c|}
\hline \multirow[t]{2}{*}{ Events } & \multicolumn{3}{|l|}{ N (\%) } & \multirow[t]{2}{*}{$P$ value } \\
\hline & Flexible (204) & Rigid (171) & Total (375) & \\
\hline Cisatracium (mg) & $10.8 \pm 3.8(n=177)$ & $11.9 \pm 3.6(n=136)$ & $11.3 \pm 3.8$ & 0.008 \\
\hline Procedure duration (min) & $41.4 \pm 32.5$ & $41.5 \pm 29.9$ & $41.1 \pm 31.3$ & 0.961 \\
\hline Awakening duration (min) & $25.3 \pm 21.0(n=179)$ & $25.8 \pm 17.3(n=144)$ & $25.6 \pm 19.4$ & 0.185 \\
\hline \multicolumn{5}{|l|}{ Perioperative adverse events } \\
\hline Failure of ventilation & 0 & 0 & 0 & 1.000 \\
\hline Bronchospasm & 0 & 0 & 0 & 1.000 \\
\hline Intraoperative cough & 0 & 0 & 0 & 1.000 \\
\hline Hypoxemia & $8(3.9 \%)$ & $5(2.9 \%)$ & $13(3.5 \%)$ & 0.779 \\
\hline Reintubation after extubation & $2(0.98 \%)$ & 0 & $2(0.5 \%)$ & 0.503 \\
\hline
\end{tabular}



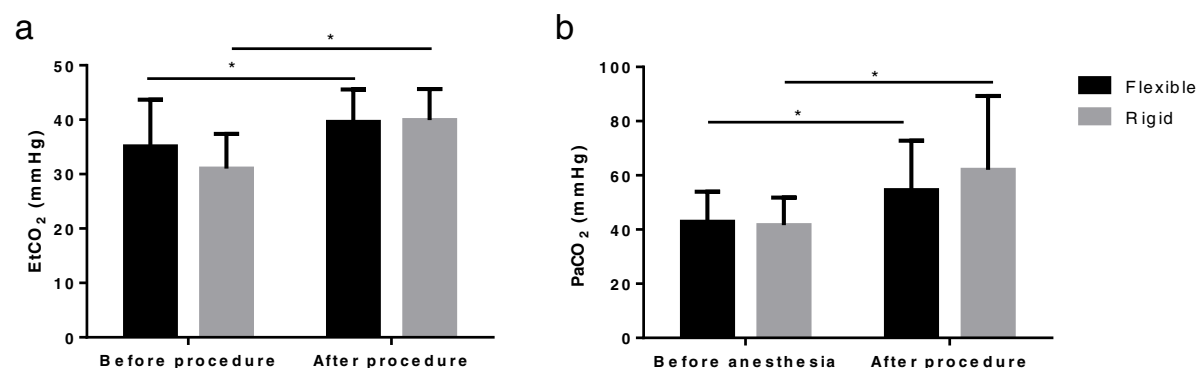

Fig. 1 Change in $\mathrm{EtCO}_{2}$ and $\mathrm{PaCO}_{2}$ before and after therapy in patients with $\mathrm{CAO}$. $\mathbf{a}$, Change in $\mathrm{EtCO}_{2}$ before and after procedure $(n=100$ in flexible group and $n=57$ in rigid group recorded in the anesthesia note). $\mathbf{b}$, Change in $\mathrm{PaCO}_{2}$ before anesthesia and after procedure ( $n=18$ in flexible group and $n=17$ in rigid group recorded in the anesthesia note). Paired t test used in these data, ${ }^{*} p<0.05$, Flexible: flexible bronchoscopy treatment; Rigid: rigid bronchoscopy treatment

Both rigid and flexible bronchoscopy are now available for the interventional pulmonologists to perform this operation for advanced diagnostic and therapeutic purposes. Flexible bronchoscopy was performed through a laryngeal mask airway or endotracheal tube, which can create auto positive end expiratory pressure and alter airway mechanics with a minimum of sedation. Rigid bronchoscopy relies on the use of a laryngoscope and either a rigid ventilating bronchoscope or Hopkins rod telescope, which can alter the airway by stenting the airway open, and often requires a deeper level of sedation [14]. There are some debates as which one is better than the other, and whether the use of muscle relaxants is safe and indispensable in this procedure [15-20]. In some articles, the authors are in favor of the non-use of muscle relaxants in rigid or flexible bronchoscopy for the safe factor $[17,21]$, but a recent research showed that controlled ventilation with muscle relaxants during stenting reduced the incidence of desaturation events, maintaining a favorable respiratory status
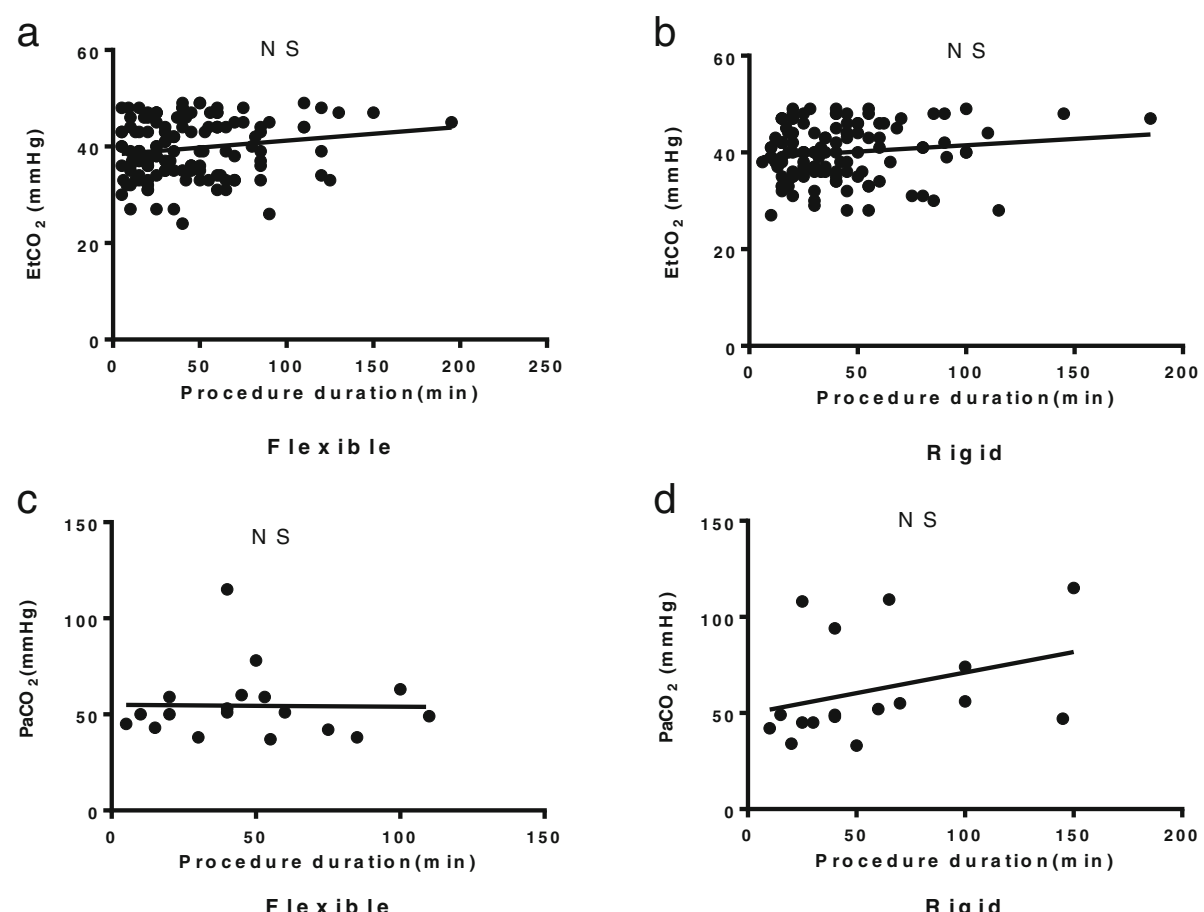

Fig. 2 The Correlation between the procedure duration and $\mathrm{EtCO}_{2}$ or $\mathrm{PaCO}_{2}$ after flexible bronchoscopy or rigid bronchoscopy therapy in patients with CAO. $\mathbf{a}, \mathbf{b}$, The correlation between the procedure duration and $\mathrm{EtCO}_{2}$ after flexible bronchoscopy and rigid bronchoscopy therapy ( $n=133$ in flexible group and $n=121$ in rigid group recorded in the anesthesia note). $\mathbf{c}, \mathbf{d}$, The correlation between the procedure duration and $\mathrm{PaCO}_{2}$ after flexible bronchoscopy and rigid bronchoscopy therapy $(n=18$ in flexible group and $n=17$ in rigid group recorded in the anesthesia note) 
Table 5 Patients with lowest $\mathrm{SPO}_{2}<95 \%$ and oxygen pressure $\left(\mathrm{PaO}_{2}\right)$ in the arterial blood gas during the therapy $\left(\mathrm{PO}_{2}: n=18\right.$ in flexible group and $n=17$ in rigid group recorded in the anesthesia note)

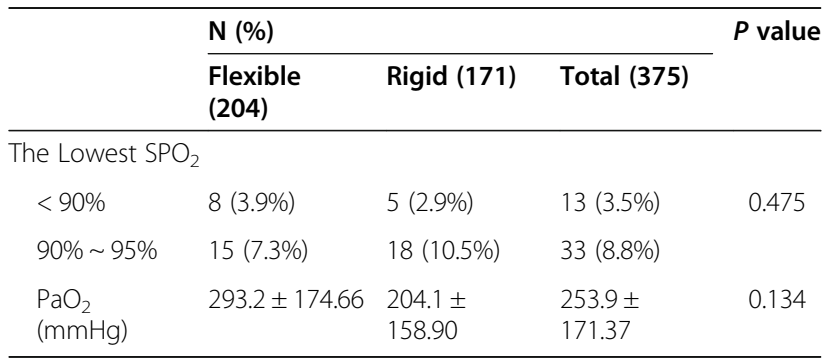

[22]. A rigid bronchoscope can be placed under deep sedation without muscle relaxants, but that required high doses of analgesic and hypnotic agents, which may lead to cardiovascular instability or residual drug effects harming pulmonary function after the operation, and if the depth of anesthesia is not enough, it may causes the trauma of the vocal cords and larynx, even accidental airway perforation, due to the significant response to tracheal manipulation. The use of topical anesthetics is recommended by the ACCP (American College of Chest Physicians) for both basic and advanced bronchoscopy as it reduces the dose of sedative agents needed and effectively decreases cough [23]. Tracheal reflexes are blunted by incorporating a 'spray-as-you-go' technique of topical lidocaine spray via the working channel of the bronchoscope [24]. The use of local anesthetics also can be observed in our research, but with the administration of muscle relaxants, which can provide good surgical conditions, the frequency and dose of local anesthetics were not so high.

In our research, we have observed that the use of muscle relaxants can facilitate the placement of rigid bronchoscope, ensure vocal cord adduction, and prevent life-threatening patient moving and coughing during the procedure, thus to provide the best operating conditions. Although SGA (supraglottic airway) insertion itself may not necessitate muscle paralysis, paralyzed vocal cords facilitates bronchoscopy in adduction position. Furthermore, muscle paralysis could attenuate the risk of patient's coughing and movements during the operation, as well as lower the chest wall resistance and reduce inspiratory pressures needed to achieve satisfactory tidal
Table 7 Binary logistic regression analysis for risk factors for postoperative ICU admission

\begin{tabular}{lll}
\hline Risk factors & OR $\mathbf{( 9 5 \% ~ C l )}$ & $\boldsymbol{P}$ value \\
\hline ASA & $0.469(0.283 \sim 0.777)$ & 0.003 \\
Dyspnea or orthopnea & $2.878(1.315 \sim 6.298)$ & 0.008 \\
\hline
\end{tabular}

volumes [25-28]. At the beginning, we also did not dare to use muscle relaxants, but with the improvement of anesthesia equipment, visual technology, and anesthesia skills, we began to experiment with muscle relaxants. Approximately $96.5 \%$ of the 375 included patients were given skeletal muscle relaxants as recorded in the anesthesia notes, no patients suffered the failure of ventilation, bronchospasm or cough, only 13 patients (8 in flexible, 5 in rigid) suffered the hypoxemia during the procedure, and two patients $(0.05 \%)$ were reintubated after awakening due to dyspnea after extubating (sent to ICU after adjusting the position of the bracket). In addition, the dosages of muscle relaxants used in rigid bronchoscopy are significantly higher than those used in the flexible bronchoscopy due to the higher degree of irritation, but that didn't affect the patient's awakening. The results may illustrate that the muscle relaxants can be safely used both in flexible and rigid bronchoscopy treatments in patients with $\mathrm{CAO}$, and more dose of muscle relaxants should be given in rigid bronchoscopy treatments.

In this process, the way of mechanical ventilation is also a key factor affecting gas exchange for the patients with $\mathrm{CAO}$ undergoing flexible or rigid bronchoscopy treatments. In the past years, high-frequency jet ventilation had become the main ventilation method for bronchoscopy in the treatment of central airway stenosis [29]. A previous study has demonstrated no difference in arterial blood gas analysis values between jet ventilation and conventional ventilation during endobronchial laser surgery, yet jet ventilation may be associated with some complications including hypertension, hypoxemia, hypercapnia, and barotrauma [23]. In this study, the traditional Low-frequency ventilation was used in all patients with $\mathrm{CAO}$. We compared $\mathrm{ETCO}_{2}, \mathrm{PaCO}_{2}$ and $\mathrm{PaO}_{2}$ between the flexible and rigid bronchoscopy group to assess whether traditional ventilation can provide adequate ventilation. Many patients with CAO already had hypoxia before surgery, and even $98.4 \%$ of the patients

Table 6 Post-operative recovery

\begin{tabular}{llll}
\hline Outcome & $\mathbf{N}$ (\%) & & Total (375) \\
\cline { 2 - 4 } & Flexible (204) & Rigid (171) & $323(86.7 \%)$ \\
\hline Ward & $177(86.8 \%)$ & $146(85.4 \%)$ & $52(13.3 \%)$ \\
ICU & $27(13.2 \%)$ & $25(14.6 \%)$ & 3.765 \\
Death in 48 h after surgery & $1(0.5 \%)$ & $2(1.2 \%)$ & $3(0.8 \%)$ \\
\hline
\end{tabular}


experienced symptoms of dyspnea [30]. Therefore, most of them inhaled oxygen when they entered the operating room for emergency bronchoscopy surgery. The $\mathrm{SpO}_{2}$ value of most patients was between 93 and $100 \%$, which couldn't reflect the true hypoxia. In addition, hypoxemia and hypercapnia may commonly occur during bronchoscopic procedures. During the procedure, we noticed $\mathrm{SpO}_{2}$ decreased in some patients, despite fraction of inspired oxygen $\left(\mathrm{FIO}_{2}\right)$ being kept at $100 \%$, but no patient suffered severe hypoxemia or hypercapnia. For patients undergoing some transient episodes of $\mathrm{SpO}_{2}$ lowering below $90 \%$, high fresh gas flows are often used to obtain adequate ventilation and compensate for the airway leakage. If it didn't work, we would remove the placed bronchoscope and then ventilate the patient for several minutes until $\mathrm{SpO}_{2}$ increased to above $95 \%$, then restart the procedure. $\mathrm{PaCO}_{2}$ values were significantly higher than preoperative level in both groups, and most patients suffered hypercapnia during the operation $\left(\mathrm{PaCO}_{2}>45 \mathrm{mmHg}\right)$, but there was no correlation between the operation time and $\mathrm{EtCO}_{2}$ or $\mathrm{PaCO}_{2}$ after the procedure both in the flexible group and rigid bronchoscopy group. Different from hypoxemia, hypercarbia is generally well tolerated unless severe enough (above 80 to $100 \mathrm{mmHg}$ ) to cause obtundation and respiratory arrest, and moderate hypercarbia may be a favorable condition in a number of pathologic situations [31]. Intraoperative hypercapnia caused by insufficient ventilation can be adjusted by hyperventilation soon after the operation completed. So in this study, there was no obvious life-threatening hypercapnia occurred. The results may show that the Low-frequency traditional ventilation also can meet the adequacy of ventilation and gas exchange in patients with $\mathrm{CAO}$ undergoing bronchoscopy therapy. Since some cases have been excluded in our study due to the possible advantages of using HFJV in these cases, including bronchopleural, bronchoesophageal and bronchomediastinal fistulae, we still don't recommend the routine use of jet ventilation in the procedures described.

In this study, most of the patients with $\mathrm{CAO}$ who underwent bronchoscopy therapy were safely transferred to the ward $(86.7 \%)$, while the others were sent to ICU postoperatively due to their poor general condition. Variables identified as increased complication rate predictors for therapeutic bronchoscopy (including both rigid and flexible) include: emergent procedures, ASA physical status scores [23]. We revealed that the grade of ASA and obvious dyspnea or orthopnea were the independent risk factors for postoperative ICU admission. Therefore, ICU admission may be a safe option when an urgent bronchoscopy is carried out in patients with severe dyspnea, or with high ASA scores. Three deaths (2 due to hemoptysis and 1 due to acute myocardial infarction) occurred during the procedures or within $48 \mathrm{~h}$ postoperatively, with a mortality rate of $0.8 \%$. The causes of these three deaths were not directly related to the procedures even though they occurred in the perioperative period. The rest of the patients $(99.2 \%)$ recovered without incidents in the recovery room in the immediate postoperative period.

There are still some limitations in our study. Firstly, we did not have a blank control group to compare the procedures performed without muscle relaxants. Secondly, a lot of blood gas data were missing from the data during the operation. And thirdly, there was a lack of studies investigating the optimal dosages of muscle relaxants, we will design some prospective researches in the future.

\section{Conclusions}

The muscle relaxants and low-frequency traditional ventilation can be safely used both in flexible and rigid bronchoscopy treatment in patients with central airway obstruction. Given the rise in the interventional therapy, bronchoscopy treatments of CAO under general anesthesia may turn more frequent in the coming future, and this research may provide a safe anesthesia management option for its implementation.

\begin{abstract}
Abbreviations
CAO: Central airway obstruction; ECG: Electrocardiograph; $\mathrm{SPO}_{2}$ : Pulse Oxygen saturation; IABP: Invasive arterial blood pressure; LMA: Laryngeal mask airway; ICU: Intensive care unit; EtCO2: End-tidal carbon dioxide; BMI : Body mass index; ASA: American Society of Anesthesiologist; $\mathrm{PaO}_{2}$ : Partial pressure of oxygen in artery; $\mathrm{PaCO}_{2}$ : Partial pressure of carbon dioxide in artery; $\mathrm{FlO}_{2}$ : Fraction of inspired oxygen; SGA: Supraglottic airway
\end{abstract}

Acknowledgements

Not applicable.

Authors' contributions

ZND conceived the original idea and collaborated on the design of the study. JJL and NL collaborated on the design of the study, were in charge of collecting the data, analyzed and interpreted the patient data, and participated in writing the manuscript. WJM and MXB were in charge of collecting the data for the study. ZYC was an active mentor throughout the study's development and substantively revised the final manuscript. All authors read and approved the final manuscript.

\section{Funding}

None.

Availability of data and materials

The data sets used and/or analyzed during the current study available from the corresponding author on reasonable request.

\section{Declarations}

Ethics approval and consent to participate

Ethical approval was provided by the Ethics Committee of The First Affiliated Hospital with Nanjing Medical University, Nanjing, Jiangsu, China (approval number: 2019-SR-505) on December 25, 2019. The requirement for written informed consent was waived due to the retrospective nature of the study.

Consent for publication

Not applicable. 


\section{Competing interests}

The authors declare that they have no competing interests.

Received: 15 August 2020 Accepted: 25 March 2021

Published online: 06 April 2021

\section{References}

1. Freitag $L$, et al. A proposed classification system of central airway stenosis. Eur Respir J. 2007;30(1):7-12.

2. Schieren M, et al. New approaches to airway Management in Tracheal Resections-a Systematic Review and Meta-analysis. J Cardiothorac Vasc Anesth. 2017;31(4):1351-8.

3. Petrella $F$, et al. Operative rigid bronchoscopy: indications, basic techniques and results. Multimedia Manual Cardio-Thoracic Surg. 2014;1:mmu006.

4. Fernando HC, Sherwood JT, Krimsky W. Endoscopic therapies and stents for benign airway disorders: where are we, and where are we heading? Ann Thorac Surg. 2010;89(6):S2183-7.

5. Oviatt PL, et al. Exercise capacity, lung function, and quality of life after interventional bronchoscopy. J Thorac Oncol. 2011;6(1):38-42.

6. Sutterlin R, et al. Influence of tracheal obstruction on the efficacy of superimposed high-frequency jet ventilation and single-frequency jet ventilation. Anesthesiology. 2015;123(4):799-809.

7. Kim HJ, et al. Clinical experience of rigid bronchoscopy in single center. Tuberc Respir Dis. 2012;72(6):486.

8. Zhou Y, et al. Anesthetic management of emergent critical tracheal stenosis. J Zhejiang Univ Sci B. 2007;8(7):522-5.

9. Li F, Liang J, Li X. Resection and reconstruction of the trachea for the treatment of upper tracheal stenosis: tracheal versus non-tracheal intubation. J Coll Physicians Surg Pak. 2018;28(11):879-81.

10. Farzanegan R, Feizabadi M, Ghorbani F, Movassaghi M, Vaziri E, Zangi M, et al. An overview of tracheal stenosis research trends and hot topics. Arch Iran Med. 2017;20:598-607.

11. Zias N, Chroneou A, Tabba MK, Gonzalez AV, et al. Post tracheostomy and post intubation tracheal stenosis: report of 31 cases and review of the literature. BMC Pulmonary Med BioMed Central. 2008;8:18.

12. Tsakiridis K, Darwiche K, Visouli AN, et al. Management of complex benign post-tracheostomy tracheal stenosis with bronchoscopic insertion of silicon tracheal stents, in patients with failed or contraindicated surgical reconstruction of trachea. J Thorac Dis. 2012;4(suppl 1):32-40.

13. Farahnak MR, Moghimi MR. Rigid bronchoscopy and tracheostomy compared to repeated dilatation of tracheal stenosis prior to tracheal resection and anastomosis; a pilot study. Polish J Surg. 2014;86(3):122-5.

14. Hysinger $E B$, et al. Differences in flexible and rigid bronchoscopy for assessment of Tracheomalacia. Laryngoscope. 2021;131(1):201-4.

15. Agarwal $R$, et al. Therapeutic rigid bronchoscopy at a tertiary care center in North India: initial experience and systematic review of Indian literature. Lung India. 2014;31(1):9.

16. Ayers ML, Beamis JF Jr. Rigid bronchoscopy in the twenty-first century. Clin Chest Med. 2001;22:355-64.

17. Ernst A, Feller-Kopman D, Becker HD, Mehta AC. Central airway obstruction. Am J Respir Crit Care Med. 2004;169:1278-97.

18. Panchabhai TS, Mehta AC. Historical perspectives of bronchoscopy. Connecting the dots. Ann Am Thorac Soc. 2015;12(5):631-41.

19. Haas AR, Vachani A, Sterman DH. Advances in diagnostic bronchoscopy. Am J Respir Crit Care Med. 2010;182(5):589-97.

20. Anwar M, et al. Infraglottic versus supraglottic jet-ventilation for endobronchial ultrasound-guided transbronchial needle aspiration. Eur J Anaesthesiol. 2020;37(11):999 Publish Ahead of Print.

21. Semaan R, Yarmus L. Rigid bronchoscopy and silicone stents in the management of central airway obstruction. J Thorac Dis. 2015;7(Suppl 4): S352-62.

22. Okamoto $\mathrm{S}$, et al. A prospective, randomized trial comparing respiratory status during anesthesia for airway stenting: spontaneous respiration versus controlled ventilation with muscle relaxants. Anesth Analg. 2020;131(3):893900.

23. de Lima A, et al. Anesthesia for interventional pulmonology procedures: a review of advanced diagnostic and therapeutic bronchoscopy. Can J Anesth. 2018;65(7):822-36.

24. Pawlowski J. Anesthetic considerations for interventional pulmonary procedures. Curr Opin Anaesthesiol. 2013;26(1):6-12.
25. Galway U, et al. Anesthetic considerations for bronchoscopic procedures: a narrative review based on the Cleveland Clinic experience. J Thorac Dis. 2019;11(7):3156-70.

26. José RJ, Shaefi S, Navani N. Anesthesia for bronchoscopy. Curr Opin Anaesthesiol. 2014;27(4):453-7.

27. Matsuda $\mathrm{N}$, Matsumoto $\mathrm{S}$, et al. Perioperative management for placement of tracheobronchial stents. J Anesth. 2006;20:113-7.

28. Goudra BG, et al. Anesthesia for advanced Bronchoscopic procedures: stateof-the-art review. Lung. 2015;193(4):453-65.

29. Rosell A, Stratakos G. Therapeutic bronchoscopy for central airway diseases. Eur Respir Rev. 2020;29(158):190178.

30. Khan A, et al. Rigid bronchoscopic interventions for central airway obstruction - an observational study. Lung India. 2020;37(2):114.

31. Bigatello L, Pesenti A. Respiratory physiology for the anesthesiologist. Anesthesiology. 2019:130(6):1064-77.

\section{Publisher's Note}

Springer Nature remains neutral with regard to jurisdictional claims in published maps and institutional affiliations.

Ready to submit your research? Choose BMC and benefit from:

- fast, convenient online submission

- thorough peer review by experienced researchers in your field

- rapid publication on acceptance

- support for research data, including large and complex data types

- gold Open Access which fosters wider collaboration and increased citations

- maximum visibility for your research: over $100 \mathrm{M}$ website views per year

At BMC, research is always in progress.

Learn more biomedcentral.com/submissions 